\title{
Os primeiros meses da agenda socioambiental de Jair Bolsonaro e o que esta nos diz sobre nossa ontologia
}

\author{
Ana Julia Vaz dos Santos \\ Recebido em maio de 2019 \\ Aceito em outubro de 2019
}

\section{RESUMO}

Este artigo tem como problema central a discussão acerca da agenda adotada pelo governo Bolsonaro (PSL), nos nove primeiros meses de mandato, caracterizadas pelo enfraquecimento de leis e órgãos de proteção e fiscalização ambiental, que estimulam o desmatamento da Floresta Amazônica. Busca-se demonstrar por meio de um diálogo com a teoria pós-estruturalista, que essa relação com o território e com outros grupos não ocidentais, está ligada a um conflito ontológico. Expõem-se ao longo do texto, detalhes de nossa ontologia atrelada à ideia de progresso, domínio sobre a natureza e seus desdobramentos na relação do homem ocidental com o ambiente e sua destruição como representados pela agenda do governo frente ao meio ambiente. Os resultados vão de encontro à ideia de que a relação humana ocidental com o meio ambiente está relacionada à lógica do 'antropoceno' correspondente à era em que os humanos se tornaram uma força capaz de destruição planetária. Além disso, a ontologia moderna mostra-se incapaz de reconhecer nossa interdependência com outras espécies apresentando resultados dramáticos. Mostra-se necessário um discurso mais eco-centrado, e a possibilidade de uma relação benéfica entre humanos e a natureza, impedindo uma agenda política de degradação ambiental e humana.

Palavras-chave: Antropoceno; Ecologia; Território; Estudos Multiespécie.

\section{ABSTRACT}

This article has as its central problem the discussion about the agenda adopted by the Bolsonaro government (PSL), in the first nine months of its mandate, characterized by the weakening of laws and environmental protection and inspection agencies, which stimulate the deforestation of the Amazon Forest. We seek to demonstrate through a dialogue with poststructuralist theory that this relationship with the territory and other non-Western groups is linked to an ontological conflict. Details of our ontology linked to the idea of progress, mastery over nature and its consequences in the relationship between western man and the environment and its destruction as represented by the government's environmental agenda are presented throughout the text. The results match the idea that Western human relations with the environment are related to the idea of the 'anthropocene' corresponding to the era in which humans became a force capable of planetary destruction. Moreover, modern ontology is unable to recognize our interdependence with other species yielding dramatic results. A more eco-centered discourse and the possibility of a beneficial relationship between humans and nature are needed, impeding a political agenda of environmental and human degradation.

Keywords: Anthropocene; Ecology; Territory; Multispecies Studies.

1 Graduanda em Ciências Sociais pela Universidade Federal do Paraná. Contato: anajuliavazs@gmail.com. 


\section{Introdução}

Eleito com um discurso de extrema direita, Jair Messias Bolsonaro (PSL) inicia seu mandato com uma agenda política que preocupa ambientalistas e populações que não estão inseridas na "lógica ocidental". Trago a discussão a agenda política de Bolsonaro referente às questões ambientais com a intenção de estabelecer uma sucinta contribuição para pensarmos nossa relação com o território, natureza e não humanos.

A questão perpassa, inevitavelmente, o modo de produção capitalista neoliberal e seu impacto no ecossistema e também a outras culturas. Entretanto, não me deterei a isso nessa discussão, embora reconheça a pertinência deste fato e a gravidade destruidora desse modo de produção. Gostaria de propor olharmos para a questão por outra abordagem explicava: a ontologia ocidental e o nosso padrão cultural que tanto criamos, e que somos frutos. Frutos esses que geram motivações, e estas, definem nosso relacionamento com a natureza, explicitados nesse sentido pela agenda política do atual presidente da República.

Da mesma maneira que a questão não é meramente economicista e perpassa a discussão ontológica, cabe frisar também, que Jair Bolsonaro não é o único presidente que causa, ou que causou ações danosas ao ecossistema brasileiro, outros governos contribuíram para isso também. A diferença é que o discurso do atual presidente deixa explícitas suas intenções de criar uma espécie de 'desenvolvimento' a custas de uma exploração incessante da natureza. Dessa maneira, o recorte escolhido - os primeiros meses do governo Bolsonaro - decorre da intenção de demonstrar de forma prática e materializada a ontologia ocidental, e a atualidade da questão. Reconhece-se, entretanto, que não se completou o primeiro ano de mandato da atual gestão, e nesse sentido, é complicado delimitar qual será definitivamente a política socioambiental desta. Entretanto, é possível construir caminhos analíticos para se entender de que maneira tais ações contrastam com uma ontologia relacional.

Com o intuito de tornar clara a relação entre as práticas políticas e perspectivas ontológicas, será realizada uma breve análise dos posicionamentos de Jair Bolsonaro na mídia em relação ao meio ambiente, os discursos em relação a este, e principalmente, as 
atitudes políticas do chefe de Estado para com a pasta ambiental. O tempo de análise são os nove primeiros meses de governo dessa gestão, e as fontes utilizadas para a constituição deste estudo são as fontes documentais jornalísticas. Além disso, o método bibliográfico é utilizado para tencionar as concepções teóricas que perpassam a discussão ontológica para contrastar com o caso prático proposto no trabalho.

Em um primeiro momento será definida a noção de ontologia dialogando com outros pesquisadores, com o intuito de demonstrar quais as características da ontologia dualista em contraposição as ontologias relacionais. Posteriormente, pretende-se demonstrar as características presentes nos posicionamentos e perspectivas de ações políticas dos primeiros meses da gestão de Bolsonaro, com vistas a contrastar as atuais políticas públicas com uma ontologia relacional. Assim sendo, pretende-se fundamentar a descrição das informações sobre o perfil político-ambiental de Bolsonaro, refletindo e dialogando com a teoria pós-estruturalista para delinear caminhos que tornarão perceptíveis a ontologia moderna em seu pensamento e posicionamentos governamentais.

Esse tema é de suma importância, pois existe muito mais complexidade nas relações entre natureza e cultura do que a visão de mundo moderno ocidental nos permite visualizar. Além disso, é imprescindível discutir a agenda política de Bolsonaro que está aprofundando uma crise social e ambiental de difícil reversão. Dessa forma, pretende-se entender as tensões que perpassam a ontologia e as práticas políticas, questionando dessa forma, aquilo que o ocidente e suas pautas vêm destruindo de forma avassaladora sem se sensibilizar com outras formas de existência, constituindo e se refletindo na agenda política do atual presidente da república.

\section{A ontologia ocidental em questão}

Gostaria de definir como entendo ontologia para posteriormente analisar o caso prático. Assimilo 'ontologia' me aproximando a percepção de Latour (2012), ontologia enquanto "modos de existência". Ainda vou de encontro ao esboço de Sáez (2012, p.15), de que "cada ponto de vista define um mundo diferente, se traduz na experiência singela de que cada sujeito age em função do que vê, e com isso realiza o que vê.” Por outras 
palavras, a ontologia é a diversidade de modos de existência que podem vir a ser materializados em práticas concretas, a visão de mundo apreendida culturalmente molda a forma como o indivíduo irá experienciar o mundo.

Em relação à ontologia ocidental, alguns autores contribuem para o entendimento de como esta opera em nosso mundo, desde a concepção de pessoa até as formas como se desenvolvem as relações com o ambiente e com outras culturas. Devido a isso, essa seção tem como objetivo demonstrar de que maneira se operam e quais as características da ontologia dualista para posteriormente contrastá-la com ontologias relacionais.

Tim Ingold (1995, p.39-53), trata acerca da concepção de ser humano no ocidente em uma encruzilhada dicotômica entre humanidade e animalidade. $\mathrm{O}$ antropólogo britânico busca responder o que é um humano e nos mostra que mesmo nos aproximando fisiologicamente dos animais nos achamos superiores. Entretanto, nosso entendimento de humano mesmo dado como superior, necessita da centralidade dos animais em sua construção: a cada geração construímos a noção de animalidade como o traço que não dispõe daquilo que o homem tem - linguagem, racionalidade e a consciência moral - e a cada geração lembramos a nós mesmos que o homem é também um animal. O que nos diferencia dos outros animais - em nossa ontologia - é a característica como espécie identificáveis pelas capacidades de raciocinar, pela linguagem, consciência moral e a cultura.

O fundamental é que Ingold (1995) mostra que a visão do que é um ser humano é resultado ontológico. No ocidente, a fronteira entre a espécie humana e as demais espécies animais não é paralela, ela cruza as fronteiras entre animalidade e humanidade com estado de ser.

Latour (1994) quando aborda a visão de mundo ocidental, traz para a discussão a ideia de 'modernidade'. Boa parte das definições da modernidade apontam para uma noção de tempo que demonstra algo novo. A modernidade é idealizada como uma aceleração, ruptura, uma revolução no tempo. Essa ruptura na passagem regular do tempo contrasta-se com os não modernos - os vencidos - de passado arcaico e estável. Essa singularidade ocidental de se enxergar como 'moderno' é um traço da necessidade que temos de nos auto afirmar como superiores em relação a outros povos, resultando 
no aparecimento em nossa ontologia da clássica concepção de hierarquização dos seres, oriunda da separação traçada pela ciência ocidental entre o sujeito detentor do conhecimento e o objeto que seriam os 'fatos' a serem conhecidos. Todavia, o infortúnio de ser moderno acarreta consequências para nós desde a forma como fazemos nossa ciência e a forma como concebemos as relações humanas e não humana, e natureza e cultura.

Reconstruindo historicamente, Latour (1994) aponta que a modernidade surge a partir da dessacralização do mundo e por meio da hegemonia que fora conquistada pelas ciências de base cartesiana e newtoniana. A modernidade surge desse modo, a partir do que se considera natureza e o que se considera por cultura. De um lado estariam os porta vozes cientistas transformando a natureza em ciência, e de outro estariam os políticos, porta vozes da cultura transformando-a em política.

Nasce dessa forma à modernidade, por meio de dois divisores construindo uma ideologia através da qual nós modernos vemos a nós mesmos e aos outros. O divisor interno opera na divisão do que é natureza e do que é cultura. A partir disso, criamos outras subdivisões - objeto e sujeito, coisa e pessoa, humano e não humano - com a exportação desse divisor para a relação com outros povos estabelece-se o grande divisor externo. Através deste, os modernos separam de um lado o ocidental que estaria representando a natureza como ela verdadeiramente é, e do outro lado estariam os "não modernos", as culturas tradicionais que na visão ocidental representam a natureza subjetiva, e dessa forma, inadequada. A modernidade ocidental nessa visão seria superiormente diferente dos outros povos, pois tem a ciência o aparato que acredita ser necessário e valorativo para se diferenciar. De qualquer forma Latour (1994) mostra que tanto o divisor interno quanto o externo possuem um padrão colonial: em primeiro lugar a cultura dominando que a natureza seja ela enquanto "recurso" seja ela enquanto o "outro", não ocidental (LATOUR, 1994, p. 43).

A hipótese que trago a presente discussão, é que nossa incapacidade enquanto ocidentais de perceber nosso "tecido" de natureza e cultura como algo idôneo torna nossa realidade repleta de divisões e hibridez, o que posteriormente, acarreta de forma incisiva efeitos em nossa relação com aquilo que entendemos como o "não humano" e até mesmo será responsável por criar pré-conceitos e uma leitura, a partir de nossas 
lentes modernas, sobre outros grupos que não compartilham da mesma forma que experienciamos o mundo. Por consequência, cria-se uma imaginária linha hierarquizante que nos diferencia em grau superior aos demais, nos dando lamentavelmente a convicção de que somos um mundo único e superior com a total liberdade para tomar decisões sobre nosso meio, independente da existência de outras vidas.

Anna Tsing (2015), também questiona e expõe como se materializa a ontologia dualista. Para ela, a ciência por influência do pensamento religioso prega uma ideia de superioridade de nós humanos sobre outras espécies, desenvolvendo uma naturalização de dominação sobre outros seres. Tsing (2015) argumenta acerca da existência de mais de uma forma de se relacionar com a natureza, e mesmo assim, o combustível que nós escolhemos foi o confinamento e a dominação sobre outras espécies. A plantação que antes era vista como satisfação e não visavam o lucro, e logo, não gerava uma destruição ambiental em larga escala, reverteu-se em nossa sociedade ao escolhermos o confinamento. Padronizando em grande escala as plantações transformamos nosso relacionamento com outras espécies aprofundando a domesticação, e intensificando e forçando a fertilidade das plantas ${ }^{2}$.

A forma com que nos relacionamos com o ambiente diz muito sobre a ontologia ocidental, um caso prático ilustra essa percepção: após o incêndio na Amazônia em agosto de 2019 que durou semanas, a indústria pecuária se aliou a ONGs para exigir que Bolsonaro tomasse medidas para deter o desmatamento. A princípio parece que essa ação foi um ato de preocupação ou até mesmo de respeito e reconhecimento da codependência que temos com o que chamamos de natureza. Longe disso, a dependência que é reconhecida e valorizada, é a dependência da natureza como fonte econômica de lucro para o agronegócio. A fala de Marcelo Britto, presidente da Associação Brasileira do Agronegócio, sintetiza a questão mostrando a preocupação meramente econômica: "Não vi o cancelamento de nenhum contrato no setor, mas as luzes vermelhas estão piscando em ritmo acelerado. Se medidas não forem tomadas, se a retórica não mudar,

${ }^{2}$ Essa padronização é de tamanha potência que em nossa modernidade concebemos como a única forma de se fazer a agricultura. 
a situação pode piorar", disse após sugerir, sem mencionar marcas, que o anúncio da H\&M e outras empresas de que não comprarão couro do Brasil "pode ser marketing”3.

O discurso anteriormente citado demonstra uma preocupação não apenas econômica, mas também está relacionado a toda uma teia de construções sobre a natureza que opera em nossa ontologia. Se ocorre um descaso, ou uma real falta de preocupação com o ecossistema, é justamente por este ser concebido como algo separado de nós 'sociedade' estabelecidos em oposição a 'natureza' constituindo o grande divisor moderno. Mas se, a preocupação é meramente econômica, é possível perceber outra característica da maneira como operamos no mundo: natureza para ser dominada ou para ser conhecida cientificamente como objeto.

Trazendo uma nova forma de pensar o divisor natureza e cultura, Philippe Descola, tornou-se um dos principais representantes da virada ontológica nas ciências sociais, rompendo com a perspectiva de que natureza e cultura são elementos distintos. Durante seu trabalho etnográfico com os indígenas Achuar na Amazônia Equatorial Descola nota que o binômio natureza e cultura não operam como elementos singulares. A natureza não era concebida como algo a ser utilizável, pois não se reconhece a noção de natureza como a forma ocidental. A ontologia Achuar mobiliza a percepção de que plantas, espíritos e animais, são dotados de alma. Logo, não há um afastamento ontológico que distingue humanos de não humanos entre esse grupo. Plantas, animais e humanos são sujeitos ativos, que participam, nesse sentido, nas relações sociais (DESCOLA, 2005, p. 23).

Similarmente, Eduardo Viveiros de Castro (1996), ao desenvolver a ideia de perspectivismo ameríndio, expõe que esta forma de estar no mundo e apreendê-lo é obviamente distinta da ocidental. No perspectivismo ameríndio ocorre a criação de uma humanidade compartilhada por meio da construção dos corpos. As elaborações indígenas apontam para uma visão de mundo onde, animais, plantas e humanos concebem sua humanidade através de um mesmo partilhamento de corpos.

De tal maneira que a categoria que unifica humanos e animais não é a animalidade, como aponta Ingold (1995), característica de nossa dualidade ontológica,

${ }^{3}$ A interlocução de Britto encontra-se presente no link: <http://bit.ly/2kqv6VZ>. 
mas o perspectivismo ameríndio nos mostra que é a humanidade a condição compartilhada pelos humanos e pelos animais, visto que, nessas ontologias operam o parecer que julga a existência de uma unidade de alma e uma multiplicidade de corpos.

A partir de uma abordagem decolonial, Arturo Escobar (2015), ao discutir sobre as ontologias políticas do direito ao território, mostra que em mundos onde se operam as ontologias relacionais, o que existe é um mundo inteiro de uma infinidade de práticas que ligam uma multiplicidade de humanos e não humanos. Para resumir, uma ontologia relacional pode ser definida como aquela em que qualquer coisa (humano ou não humano) preexiste relações que constitui. Todos nós existimos porque tudo existe.

Exposto como as formas ontológicas apreendidas pelos grupos humanos influenciam o entorno e a experiencialização da existência pelas pessoas, a ontologia também se refletiria na forma como se faz política, neste caso, na agenda política do atual presidente.

\title{
As ações de Bolsonaro nos primeiros meses de governo
}

\begin{abstract}
A floresta está viva. Só vai morrer se os brancos insistirem em destruí-la. Se conseguirem os rios vão desaparecer debaixo da terra, o chão vai se desfazer, as árvores vão murchar e as pedras vão rachar no calor. A terra ressecada ficará vazia e silenciosa. Os espíritos xapiri, que descem das montanhas para brincar na floresta em seus espelhos, fugirão para muito longe. Seus pais, os xamãs, não poderão mais chamá-los e fazê-los dançar para nos proteger. Não serão capazes de espantar as fumaças de epidemias que nos devoram. Não conseguirão mais conter os seres maléficos, que transformarão a floresta num caos. Então morreremos, um atrás do outro, tanto os brancos quanto nós. Todos os xamãs vão acabar morrendo. Quando não houver mais nenhum deles vivo para sustentar o céu, ele vai desabar (Davi Kopenawa - A queda do céu. 2016, p. 5).
\end{abstract}

Questão ambiental só importa aos veganos que comem só vegetais (Jair Bolsonaro, julho de 2019).

É proposital iniciar este tópico com essas duas passagens que contrastam de forma clara e precisa as formas de relações que o ocidente desenvolve com aquilo que concebemos como natureza. Na primeira passagem, nota-se ao longo da fala do xamã Yanomami, Davi Kopenawa, que a relação natureza e cultura são parte de um mesmo campo sociocósmico onde, a destruição da floresta pelos brancos, estaria diretamente relacionada a um impacto direto em todas as áreas da vida Yanomami e também em nossa. Em contrapartida, a fala do atual presidente da república Jair Bolsonaro (PSL), retrata de forma concisa a ontologia ocidental ligada a ideia de progresso, separação 
entre natureza e cultura e principalmente um domínio e até mesmo um descaso com a natureza de forma destruidora. Bolsonaro, vê o meio ambiente como uma forma de apropriação para o enriquecimento financeiro. Ao ser questionado nesta ocasião pela sua intenção de transformar a região da baía de Angra dos Reis, em uma "Cancún brasileira"4 visando o lucro, visto como uma forma de progresso, ignora que o local é hoje uma área de preservação de espécies ameaçadas de extinção.

As atitudes políticas de Bolsonaro (PSL) são muito mais graves que um "deboche" com veganos como exposto anteriormente. Logo no início de seu mandato, Jair Bolsonaro tentou fundir o Ministério do Meio Ambiente com o Ministério da Agricultura5, além de propor que este último tornar-se-ia responsável pela identificação, delimitação, demarcação e pelos registros de terras indígenas e quilombolas, competências exercidas pela Funai (Fundação Nacional do Índio) e pelo Incra (Instituto Nacional de Colonização e Reforma Agrária) ${ }^{6}$. Essa ação supõe claramente um envolvimento em uma disputa ontológica, visto que, as duas pastas tem competências distintas e representam interesses completamente opostos que eventualmente mostrarse-ia uma relação demasiadamente conflitiva, favorecendo o lado mais forte: o lado dos ruralistas.

Derrotado nessas questões nomeou como Ministro do Meio Ambiente, Ricardo Salles acusado pelo Ministério Público de fraudar processo do plano de manejo da área de proteção ambiental da várzea do rio Tietê, em 2016, quando estava à frente da pasta do Meio Ambiente do governo de Geraldo Alckmin (PSDB)7. Além disso, Bolsonaro questionou a divulgação de dados do INPE (Instituto Nacional de Pesquisas Espaciais) sobre desmatamentos no Brasil, alegando que a ação prejudicaria o país ${ }^{8}$. Estes exemplos de ações remetem a um aumento demasiado de destruição ambiental precipitando um colapso de difícil reversão em nome do lucro.

Arturo Escobar (2015, p. 93) afirmou que a modernidade ocidental adotou a categoria "Mundo" para si própria. Por essa noção de mundo, entende-se civilizado, livre

\footnotetext{
4 Para mais informações ver em: <https://glo.bo/2lIYF56>.

5 Para mais informações ver em: <http://bit.ly/2m7tCQT>.

${ }^{6}$ Para mais informações ver em: <https://glo.bo/2kyGkaP>.

7 Disponível em: <https://glo.bo/2lIxEPy>.

${ }^{8}$ Disponível em: <https://glo.bo/2lIxp76>.
} 
e racional. Ao adotar essa categoria o ocidente nega outros mundos, outras formas de viver e de existir, que são distintas. Essa modernidade estaria baseada em uma "ontologia dualista", que separa o humano do não humano, a natureza da cultura, indivíduo e sociedade, nós e eles, etc. Logo, nossa ontologia dualista reflete naquilo que somos, fazemos, pensamos. Escobar propõe o termo "ontologia política” para falar dos múltiplos mundos como aqueles dos povos indígenas, quilombolas, afrodescendentes, camponeses, e tantos outros. Suas lutas, existências e resistências seria uma luta pela defesa do pluriverso contendo várias formas de viver, aquilo que nós ocidentais estamos destruindo e que nesse caso, são bem visíveis na agenda política do atual presidente da república.

É interessante pensar que, não apenas nossa ontologia torna-se um problema na forma como se estabelece nossa relação com o ecossistema, mas também a intensidade destruidora que isso acarreta quando há uma combinação entre ela e o sistema capitalista neoliberal: natureza e igualdade com outras formas de mundo não se enquadram no desenvolvimento de um mundo único esperado e necessário pelo capitalismo frenético, tornando-se impossível de coexistirem sem contradições. Como apontou Giddens (1991, p. 68), o sistema capitalista envolve uma natureza fortemente competitiva e expansionista constante, quanto a questão ambiental, a atual crise deve a sua razão primordial às contradições inerentes ao modo de produção capitalista. James O'Connor (2002), nos mostra que as crises ambientais derivam do que ele chamou de uma crise de custos das condições de produção. O capitalismo é tão degradante que intensifica a demanda por mais capital para manter o mesmo nível de lucratividade mediante o declínio das suas condições de produção. Não vivemos mais em um período onde o processo produtivo contava com supostas fontes inesgotáveis de recursos materiais, hoje o sistema depara-se com impedimentos ecológicos às atividades econômicas (MONTIBELLER-FILHO, 2001).

Não é à toa que a dialética entre nossa ontologia e o modo de produção capitalista, levantaram a discussão de que hoje estamos no período de tempo em que muitos pesquisadores o chamam de Antropoceno: a era em que os humanos se tornaram uma força capaz de destruição planetária. Para Haraway (2016, p. 139), “Chegamos em um ponto em que trata-se de mais do que 'mudanças climáticas'; trata-se também da 
enorme carga de produtos químicos tóxicos, de mineração, de esgotamento de lagos e rios, sob e acima do solo, de simplificação de ecossistemas, de grandes genocídios de pessoas e outros seres, em padrões sistemicamente ligados que podem gerar repetidos e devastadores colapsos do sistema." A recursividade do processo pode ser terrível, em nome do progresso.

Um acontecimento marcante que demonstra nossa relação com o ambiente ocorreu no dia 29 de julho de 2019, o dia em que a Terra entrou em sobrecarga após a sociedade e a economia global ultrapassarem a capacidade do ecossistema terrestre. A partir desse dia passamos a utilizar mais do que o ecossistema mundial consegue renovar anualmente passando a utilizar o estoque da natureza. ${ }^{9}$ Noticiado em diversas mídias, à estimativa da Global Footprint Network ${ }^{10}$ apontou que se todas as pessoas do planeta tivessem o mesmo estilo de vida dos estadunidenses precisaríamos de aproximadamente cinco planetas Terra para sustentar essa forma de viver. ${ }^{11}$ A questão que permanecem ainda é: Quais motivos que levam a invejar esse estilo de vida norte americano mesmo sabendo que isso levará a consequências terríveis em nome de um progresso, de um ganho financeiro? Afirmar que o sistema capitalista é o responsável pela degradação ambiental é correto. Não há desenvolvimento sustentável no capitalismo e este sistema tem contribuído para que ocorra uma aceleração na degradação ambiental, mas a questão ainda é mais profunda, a questão também é ontológica.

Durante a reunião com governadores em agosto $^{12}$, com a intenção de expor as ações que o governo federal estava realizando para combater os incêndios na Amazônia, Bolsonaro afirmou que haviam mais de 400 pedidos de demarcação de terra indígena em processo de tramitação no Ministério da Justiça e que estas levariam a uma inviabilização de desenvolvimento do país. Nas palavras do presidente, áreas de proteção ambiental, quilombos e parques nacionais levariam a uma insolvência do Brasil.

9 Para saber mais ver em: <http://bit.ly/2lCpMzı>.

${ }^{10}$ A Global Footprint Network é uma organização internacional pioneira em calcular a pegada ecológica que contabiliza o quanto de recurso natural é usado para as necessidades de um indivíduo ou população.

${ }^{11}$ Disponível em: <http://bit.ly/2miNowY>.

${ }^{12}$ A reunião foi o resultado de uma crise política que o governo enfrentou após ocorrer um incêndio na Floresta Amazônica em agosto de 2019, os incêndios queimaram equivalente a 4,2 milhões de campos de futebol. Para saber mais: <http://bit.ly/2XEJTLV>. 
A ideia de um desenvolvimento demonstra de forma concisa a relação com o ambiente e a forma como se estabelece uma ontologia dualista. Se em Latour (1994), ele nos mostra que a ideia de modernidade traz consigo uma ideia de revolução no tempo, Porto-Gonçalves (2004, p. 24) complementa ao mostrar que “desenvolvimento é o nome síntese da ideia de dominação da natureza. Afinal, ser desenvolvido é ser urbano, é ser industrializado, enfim, é ser tudo aquilo que nos afaste da natureza e que nos coloque diante de constructos humanos, como a cidade, como a indústria." E de fato, essa percepção está de forma inegável presente no discurso do chefe de Estado Brasileiro e sua visão de ambiente e desenvolvimento eurocêntrica.

Em seu discurso na ONU, ${ }^{13}$ Bolsonaro afirmou:

Em primeiro lugar, meu governo tem um compromisso solene com a preservação do meio ambiente e do desenvolvimento sustentável em benefício do Brasil e do mundo. [...] Hoje, 14\% do território brasileiro está demarcado como terra indígena, mas é preciso entender que nossos nativos são seres humanos, exatamente como qualquer um de nós. Eles querem e merecem usufruir dos mesmos direitos de que todos nós. Quero deixar claro: o Brasil não vai aumentar para $20 \%$ sua área já demarcada como terra indígena, como alguns chefes de Estados gostariam que acontecesse. [...] Existem, no Brasil, 225 povos indígenas, além de referências de 70 tribos vivendo em locais isolados. Cada povo ou tribo com seu cacique, sua cultura, suas tradições, seus costumes e principalmente sua forma de ver o mundo. A visão de um líder indígena não representa a de todos os índios brasileiros.

Embora reconheça a diversidade cultural dos povos indígenas, Jair Bolsonaro ainda delineia sua perspectiva etnocêntrica ao afirmar "eles querem e merecem usufruir dos mesmos direitos de que todos nós". Embora a primeira vista possa parecer um discurso plural e humanista, ainda está presente uma disputa de poder assimilacionista para com os povos indígenas, com a intenção de enquadrá-los em uma 'modernidade' dominando-os dessa maneira, para abrir caminhos para a exploração do meio ambiente que por conseguinte acarretaria em um 'desenvolvimento'. Todavia, Escobar (2004, p. 98) alerta que "Y entre mayor se ala disponibilidade de considerar em pie de igualdad a los grupos subasternos, mayor es la presión ejercida sobre ellos para que nieguen su diferencia a través de conflictivas formas de assimilacion.”.

\footnotetext{
${ }^{13} \mathrm{O}$ discurso de Bolsonaro na ONU ocorreu durante o dia 24 de setembro de 2019 na abertura da Assembléia Geral das Nações Unidas e está disponível em: $<$ www.youtube.com/watch?v=7OfUQd45ETw $>$.
} 
Há algo em torno da palavra desenvolvimento que remete a ideia de progresso e cria-se um discurso por trás dessa palavra, que difunde a perspectiva de que é necessário impulsionar o mercado, economia por meio de megaprojetos com a justificativa de que essa exploração incessante da natureza e a criação destes projetos alavancarão o mercado de trabalho e, por conseguinte, qualidade de vida das pessoas aumentará. É dessa forma, que a ideologia do desenvolvimento funciona tão bem.

Entretanto, no ocidente, pouco se pergunta quanto às questões ambientais. É justamente pela forma com que concebemos o mundo não de forma relacional; pois criamos a divisão de natureza e de cultura. A primeira como um objeto e meio para ser explorada e algo aparte de nós, sociedade. Assim se tornam tão banais ou pouco importantes, os resultados desastrosos consequentes de megaprojetos que visam o desenvolvimento econômico. Ocorre uma espécie de escalonamento de importância: primeiro o desenvolvimento de 'nós' sociedade e por fim o 'outro' a natureza. O que sobra de resultado dessa divisão natureza e cultura na prática por meio desses megaprojetos se torna visível por meio da poluição de rios e lagos, devastações de vegetações nativas e a exploração da mão de obra local, sem o reconhecimento da interdependência da agência não humana (plantas e animais, aquilo que está no plano da natureza) em nosso mundo relacional.

Há uma ausência de consideração sobre o verdadeiro sentido que a palavra desenvolvimento tem para grupos não ocidentais como também para a importância do lugar para a constituição cultural do grupo, não há um diálogo de saberes. Como aponta Porto Gonçalves (2004, p. 39), “des-envolver é tirar o envolvimento (a autonomia) que cada cultura e cada povo mantém com o seu espaço, com seu território; é subverter o modo como cada povo mantém suas próprias relações de homens (e mulheres) entre si e destas com a natureza."

A disputa ontológica com grupos não ocidentais pelo ambiente e a concepção de natureza enquanto uma forma de recurso e lucro, também se delineia em outro fato que ocorreu ao longo desses primeiros meses de mandato da atual gestão. O jornal online The Intercept Brasil, divulgou documentos inéditos que mostravam um plano 
governamental de desenvolvimento e ocupação da Amazônia' ${ }^{14}$, conhecido como projeto Barão do Rio Branco, e gestados pela Secretaria de Assuntos Estratégicos, o projeto propõe povoar a Amazônia e desenvolvê-la sob a alegação de proteger as fronteiras.

Como mostram os documentos vazados, as reuniões têm ocorrido desde fevereiro de 2019 a portas fechadas, com o objetivo de criar um plano de atração de populações não indígenas e impulsionar mega projetos com vistas a aumentar a participação da região no PIB (Produto Interno Bruto) brasileiro. Os documentos também revelaram que o atual governo vê o potencial hidrelétrico, terras cultiváveis, e minérios para exploração. O jornal The Intercept Brasil, ainda revelou que nos slides durante as reuniões mostravam excertos que delineiam claramente que a atual gestão concebe indígenas e quilombolas, como um empecilho à presença do Estado no local. E sem a presença do Estado no local, na lógica moderna não há desenvolvimento. Segundo os participantes da reunião - como mostra o jornal - a atual situação econômica do Brasil está relacionada com alguns paradigmas: "indigenismo", do "quilombolismo" e do "ambientalismo". As populações tradicionais seriam uma espécie de "massa de manobra" por ONGs internacionais para impedir que as riquezas da região fossem usadas "para o bem comum". Mas que o objetivo tornar-se-ia criar um "novo paradigma”, com o Governo Bolsonaro, esse paradigma seria o paradigma do "liberalismo" e do “conservadorismo".

Se na imprensa internacional, Bolsonaro diz que defende um desenvolvimento sustentável para o Brasil, na prática ocorre o oposto. Sua agenda político-ambiental até então tem sido, perpassada por discursos e atitudes que dizem respeito e estão diretamente ligadas às concepções ocidentais de experienciação do mundo e dominação deste. O plano Barão do Rio Branco e a ideia de que o país está cercado de paradigmas não ocidentais e que estes constituem um problema ao país, suscitam algumas questões: por que há nesse caso um discurso violento em nome da civilização em curso e contra as populações indígenas, ambientalistas, e até mesmo com aquilo que concebemos por natureza? Por que tanto interesse nessas terras? Sem dúvida podemos voltar a encontrar

14 Para saber mais informações sobre o 'projeto Barão do Rio Branco' acessar: theintercept.com/2019/og/19/plano-bolsonaro-paranoia-amazonia/ 
respostas mais uma vez na dinâmica do capital global e nacional. Contudo, essa resposta, é suficiente?

É claro mais uma vez que o discurso de Bolsonaro delineia uma disputa ontológica pelos direitos do território. Embora, como aponta Escobar (2015), às ontologias relacionais caracterizam muitos povos étnico-territoriais, elas não são limitadas para estes (na verdade, dentro da mesma experiência da modernidade ocidental há expressões de mundos relacionais, mas não são dominantes). O importante a salientar é que a pressão sobre os territórios que hoje é evidente em todo o mundo especialmente para a mineração e os agropecuários - pode ser vista como uma verdadeira guerra contra os mundos relacionais e uma tentativa adicional de desmantelar todo o coletivo. Dessa maneira, não surpreende que indígenas e ambientalistas não tenham participado das reuniões do Plano Barão do Rio Branco, muito menos que o atual presidente não pretenda realizar a demarcação de terras indígenas. Dentro desta complexa situação, as lutas pelos territórios tornam-se uma luta pela defesa dos muitos mundos que habitam o planeta.

\section{Considerações finais}

Procurei mostrar ao longo do desenvolvimento desse texto que uma das possibilidades de explicar a relação entre nós humanos ocidentais - tendo como objeto a agenda política do atual presidente da república, Jair Bolsonaro - com o meio ambiente e para com os grupos não ocidentais, pode ser explicada além de um discurso econômico do capitalismo neoliberal, mas como uma questão de visão de mundo.

É possível concluir que nossa ontologia moderna se reflete naquilo que somos, fazemos e valorizamos em nossa cultura. É necessário ressaltar que as características que nos torna modernos como a visão de mundo dualista marcada pela divisão entre humano e não humano, natureza e cultura, indivíduo e comunidade, razão e emoção, nós e eles, podem vir a ser, e normalmente se torna, um empecilho para uma relação harmoniosa com aquilo que entendemos como não humanos. Temos a tendência a nos achar superiores em relação à outra espécies, não é de se surpreender que a noção de 
superioridade possa virar uma tendência a dominar os não humanos tornando prejudicial o convívio tanto para nós quanto para o ambiente.

É necessário falar de ontologia, pois, é uma forma de higiene conceitual, uma forma de despojar-se do eurocentrismo e do antropocentrismo, para ir a um nível mais elementar da construção da vida coletiva, em que não vá prejudicar a identidade das entidades que compõem o mundo em que vivemos.

As formas de relação interespécies são variáveis de cultura para cultura, e existe muito mais complexidade na relação de naturezas-culturas e humanos e não humanos que podemos compreender, pois, nossa visão de mundo é a moderna, nosso entendimento em relação a isso se limita a nós como o centro. Torna-se difícil analisar de outro viés devido ao fato de nossa ontologia não ser relacional (ESCOBAR, 2015). As coisas existem porque tudo existe. Humano e não humano preexistem relações que constitui. Mas somos modernos e é difícil conceber isso.

A ontologia moderna mostra-se incapaz de reconhecer nossa interdependência com outras espécies e com o ambiente apresentando resultados dramáticos a outras espécies e a outros grupos humanos que não estão na mesma lógica de desenvolvimento. Percebe-se esse fato, quando dados nos mostram que o desmatamento da Amazônia aumentou 268\% em relação a $2017^{15}$. Mostra-se necessário um discurso mais ecocentrado reconhecendo a importância à possibilidade de uma relação benéfica entre humanos e a natureza para que possamos dessa forma impedir uma agenda política de degradação ambiental e humana. Quando afirmo essa sentença, não espero uma virada ontológica, no sentido de que o ocidente se transforme e adquira uma visão animista do mundo. Isso não é possível: um esquema se torna um modo de identificação quando se inibem outras formas de inferência. Não fará sentido para o nós se passarmos a dizer que plantas e animais possuem almas e vivem em sociedade realizando ações, soará bizarro para nós. Justamente, porque durante nossa socialização naturalista inibimos progressivamente as inferências que poderiam nos levar a ter essas percepções de mundo. Todavia, habitamos o mundo numa rede de dependência de diversas relações tanto humanas quanto não humanas, é necessário cuidar e gerar a possibilidade de uma

${ }^{15}$ Disponível em: http://bit.ly/2lD8EsW 
relação harmoniosa com o entorno, pois também somos dependentes deste. É necessário frear os desdobramentos negativos consequentes da ontologia dualista. Como disse Davi Kopenawa, "meio ambiente é o que resta do que vocês destruíram" (ALBERT, 1995, p. 20), torna-se urgente desse modo, a defesa de um pluriverso que respeite a variedade de vida que resistem ainda contra esse mundo único que o ocidente insiste em construir (ESCOBAR, 2015, p. 199).

\section{Referências}

ALBERT, Bruce. O ouro canibal e a queda do céu: uma crítica xamânica da economia política da natureza. Brasília: Série Antropologia. UNB, 1995.

DESCOLA, Philippe. Par-delà nature et culture. Paris: Gallimard, 2005.

ESCOBAR, Arturo. Territórios da diferença: a ontologia política dos "direitos ao território". Curitiba: Desenvolvimento Meio Ambiente, v.35, p.89-199, dezembro 2015. ESCOBAR, Beyond the third world: imperial globality, global coloniality and antiglobalisation social movements. Third World Quaterly. Vol 25, N 1. 2004.

GIDDENS, Anthony. As Consequências da Modernidade. São Paulo: Editora Unesp, 1991.

HARRAWAY, Donna. Antropoceno, Capitaloceno, Plantationoceno, Chthuluceno: fazendo parentes. Campinas: Climacom Cultura Científica - pesquisa, jornalismo e arte I Ano 3 - n. 5, abril de 2016.

INGOLD, Tim. Humanidade e Animalidade'. São Paulo: Revista Brasileira de Ciências Sociais, n. 28, 1995.

KOPENAWA, Davi. ALBERT, Bruce. A queda do céu: Palavras de um xamã yanomami. São Paulo: Companhia das Letras, 2015.

LATOUR, Bruno. Jamais fomos modernos: ensaio de antropologia simétrica. Rio de Janeiro: Editora 34, 2001.

LATOUR, Bruno.. Enquête sur les modes d'existence: une anthropologie des Modernes. Paris: La Découverte, 2012.

MONTIBELLER-FILHO, G. O mito do desenvolvimento sustentável. Florianópolis: UFSC, 2001. 
O'CONNOR, J. ¿Es posible el Capitalismo sostenible? In: ALIMONDA, H. (Org.). Ecología política, naturaleza, sociedad y utopía. Buenos Aires: CLACSO, 2002.

PORTO-GONCALVES, Carlos Walter. O desafio ambiental. Rio de Janeiro: Record, 2004 .

SÁEZ, Oscar Calavia. Do perspectivismo ameríndio ao índio real. Curitiba: Campos, n. 13, n. 2, 2011.

TSING, Anna. Margens Indomáveis: cogumelos como espécies companheiras. Florianópolis: Ilha, v.17, n.1, 2015.

VIVEIROS DE CASTRO, Eduardo. Os pronomes cosmológicos e o perspectivismo ameríndio. Rio de Janeiro: Mana, 2 (2), 1996.

Documentação jornalística:

Aumento de $268 \%$ no desmatamento, saída do acordo de Paris, Mineração e grandes obras: A Amazônia no governo Bolsonaro. INESC. 19 de out. 2018. Disponível em: http://bit.ly/2lD8EsW. Acesso em o8 de set. de 2019.

Bolsonaro diz que divulgação de dados do inpe sobre desmatamento dificulta negociações comerciais. G1. 22 de jul. 2019 Disponível em: https://glo.bo/2llxp76 Acesso em: o8 de set. de 2019.

Bolsonaro diz que reservas indígenas têm a intenção de inviabilizar o país. UOL. 27 de ago. 2019. Disponível em: http://bit.ly/2XEJTLV Acesso em 29 de ago. 2019.

Bolsonaro recua de fusão de Ambiente e Agricultura e diz não querer xiita ambiental. Folha de S. Paulo. 1 de nov. 2018. Disponível em: http://bit.ly/2m7tCQT Acesso em: o8 de set. de 2019 .

Bolsonaro transfere para a agricultura as atribuições sobre demarcação de terras indígenas e quilombolas. G1. 2 de jan. 2019. Disponível em: https://glo.bo/2kyGkaP Acesso em: o8 de set. de 2019.

Discurso de Bolsonaro na ONU. Disponível em: youtube.com/watch?v=7OfUQd45ETw Acesso em 24 de set. de 2019.

Earth Overshoot Day 2019 is July 29th, the earliest ever. WWF. 29 de jul. 2019. Disponível em: http://bit.ly/2miNowY Acesso em: 8 de set. de 2019.

Incêndios na Amazônia: Indústria agropecuária do Brasil se alinha a ONGs para exigir que Bolsonaro detenha o desmatamento. El País. 7 de set. de 2019. Disponível em: http://bit.ly/2kqv6VZ Acesso em: o8 de set. de 2019.

Justiça de SP condena futuro ministro do meio ambiente por improbidade administrativa. G1. 19 de dez. 2019. Disponível em: https://glo.bo/2llxEPy acesso em: o8 de set. de 2019 . 
O plano paranoico de Bolsonaro para a Amazônia. The Intercept Brasil. 19 de set. 2019. Disponível em: https://theintercept.com/2019/o9/19/plano-bolsonaro-paranoiaamazonia/ Acesso em 24 de set. de 2019.

Sobrecarga da Terra 2019: Planeta atinge esgotamento de recursos naturais mais cedo em toda a série histórica. G1. 29 de jul. de 2019. Disponível em: https://glo.bo/2OdNugF Acesso em: o8 de set. 2019.

Questão ambiental só importa 'aos veganos que comem só vegetais', diz Bolsonaro. O Globo. 27 de jul. 2019. Disponível em: https://glo.bo/2lIYF56 Acesso em o8 de set. de 2019. 